\title{
PENGARUH KREATIVITAS SISWA DALAM MODEL PEMBELAJARAN PROBLEM BASED LEARNING TERHADAP PRESTASI BELAJAR SISWA KELAS IV SDN KALISARI 01
}

\author{
${ }^{1}$ Zuyyinatul Aslach, ${ }^{2}$ Jupriyanto, ${ }^{3}$ Yunita Sari \\ 1.
}

Prodi PGSD FKIP Unissula

\begin{abstract}
ABSTRAK
Penelitian berfokus pada pengaruh kreativitas siswa dalam model pembelajaran problem based learning terhadap prestasi belajar siswa pada mata pelajaran IPA kelas IV SDN Kalisari 01. Adapun tujuan dari penelitian yaitu untuk mengetahui pengaruh kreativitas siswa dalam model pembelajaran problem based learning terhadap prestasi belajar siswa pada mata pelajaran IPA kelas IV SDN Kalisari 01. Penelitian ini menggunakan pendekatan quasi experimental design. Penelitian ini mengambil bentuk desainnya adalah nonequivalent control group design dengan dua kelompok yaitu kelompok kontrol dan kelompok eksperimen dengan menggunakan 2 (dua) teknik dalam pengambilan data yaitu tes dan non-tes dengan menggunakan observasi, dokumentasi dan uji coba soal. Berdasarkan hasil penelitian, terdapat pengaruh Kreatifitas Siswa dalam Model Pembelajaran Problem Based Learning (PBL) dengan hasil $66 \%$. Hal tersebut berarti kreatifitas siswa dalam model pembelajaran Problem Based Learning (PBL) baik. Prestasi belajar IPA pada siswa kelas IV SD Negeri Kalisari 01 materi gaya magnetis dan non-magnetis dengan menerapkan model pembelajaran Problem Based Learning (PBL) berpengaruh terhadap prestasi belajar siswa yang diperoleh dari rata-rata kelas eksperimen 93,93 dan pada kelas kontrol dengan rata-rata 91,96. Rata-rata nilai pre test yang diperoleh kelas IVA sedikit lebih unggul dari pada rata-rata kelas IVB. Oleh karena itu, kelas IVB dijadikan sebagai kelas eksperimen, dan kelas IVA dijadikan sebagai kelas kontrol. Hasil pretest pada kedua kelas selanjutnya dianalisis dengan uji normalitas, uji homogenitas, dan uji kesamaan dua rata-rata sebagai pemenuhan uji syarat sampel. Hal ini menunjukkan adanya pengaruh model pembelajaran Problem Based Learning (PBL) terhadap prestasi belajar siswa.

Kata kunci : kreativitas, model pembelajaran, problem based learning, prestasi, belajar
\end{abstract}

THE INFLUENCE OF CREATIVITY IN PROBLEM-BASED LEARNING FOR STUDENTS ACHIEVEMENT OF $4^{\text {TH }}$ GRADE STUDENTS IN SDN KALISARI 01

\author{
${ }^{1}$ Zuyyinatul Aslach, ${ }^{2}$ Jupriyanto, ${ }^{3}$ Yunita Sari \\ 19aslachzuyyinatul3@gmail.com, ${ }^{2}$ Jupriyanto@unissula.ac.id, ${ }^{3}$ Yunita_Sari@unissula.ac.id \\ Prodi PGSD FKIP Unissula
}

\begin{abstract}
The research focuses on the effect of students' creativity iniproblemibased learningilearning models onistudent achievementlin science subjects class IV SDN Kalisari 01. Theipurpose ofithis research is to determine the effect of student creativity in problemibasedilearningnlearning models on student achievement in science subjects class IV SDN Kalisari 01. This study uses aiquasiiexperimental design approach. This research takes the form of designnis nonequivalentncontrol groupndesign with two groups,namely thencontrol groupnand thenexperimental groupnusing 2 (two) data collectionntechniques, namely tests and non-tests. Basedionithe results of the study, there is an influence of Student Creativity in Problem Based Learning (PBL) Learning Modeliwith 66\% results. That means students' creativity in PBL was good. Natural science learning achievement in grade IV students of SDN Kalisari 01 magnetic and
\end{abstract}

30 | Jurnal Ilmiah "Pendidikan Dasar” Vol. VII No. 1 Januari 2020 
non-magnetic learning materials by applying PBL model affected student learning achievement obtained from the average experimental class 93.93 and the control class with average average 91.96. This shows the influenceiof PBL models on student achievement.

Keywords: creativity, learning models, problem based learning, achievement, learning

\section{PENDAHULUAN}

\author{
Pendidikan merupakan media \\ untuk mencerdaskan kehidupan bangsa.
} Pendidikan merupakan tonggak kuat untuk mengentaskan kemiskinan pengetahuan, menyelesaikan persoalan kebodohan, dan menuntaskan segala permasalahan bangsa yang selama ini terjadi. Peran pendidikan jelas merupakan hal signifikan dan sentral karena pendidikan memberikan pembukaan dan perluasan pengetahuan sehingga bangsa ini betul-betul melek terhadap kehidupan berbangsa dan bernegara. Pendidikan dihadirkan untuk mengantarkan bangsa ini menjadi bangsa yang beradab dan berbudaya.

Pendidikan menurut UndangUndang Nomor 20 Tahun 2003 Tentang Sistem Pendidikan Nasional adalah usaha sadar dan terencana untuk mewujudkan suasana belajar dan proses pembelajaran agar peserta didik secara aktif mengembangkan potensi dirinya untuk memiliki kekuatan spiritual keagamaan, pengendalian diri, kepribadian, kecerdasan, akhlak mulia, serta keterampilan yang diperlukan dirinya dan masyarakat. Tujuan pendidikan nasional adalah mencerdaskan kehidupan bangsa dan mengembangkan manusia Indonesia seutuhnya, yaitu manusia yang beriman dan bertaqwa terhadap Tuhan Yang Maha Esa dan berbudi pekerti luhur, memiliki pengetahuan dan keterampilan, kesehatan jasmani dan rohani, kepribadian yang mantap dan mandiri serta rasa tanggung jawab kemasyarakatan dan kebangsaan. Permasalahan mutu pendidikan seringkali dikaitkan dengan merosotnya prestasi belajar yang dicapai siswa.

Menurut Ahmadi, A dan Supriyono, W. (2013: 104) dalam proses belajar mengajar, guru mempunyai tugas untuk mendorong, membimbing dan memberikan fasilitas belajar bagi siswa untuk mencapai tujuan. Guru mempunyai tanggung jawab untuk melihat segala sesuatu yang terjadi dalam kelas untuk membantu proses perkembangan siswa. Penyampaian materi pelajaran hanyalah merupakan salah satu dari berbagai kegiatan dalam belajar sebagai suatu proses yang dinamis dalam segala fase dan proses perkembangan anak. Setiap manusia memerlukan belajar untuk mengembangkan pengetahuan yang dimilikinya, karena dapat mengacu pada perubahan perilaku individu sebagai akibat dari proses

31 I Jurnal Ilmiah “Pendidikan Dasar” Vol. VII No. 1 Januari 2020 
pengalaman (interaksi siswa dengan lingkungannya) baik yang dialami ataupun yang sengaja di rancang secara umum belajar adalah suatu perubahan di dalam kepribadian membentuk kecakapan, sikap, kebiasaan, kepandaian, atau suatu pengertian. Secara garis besar belajar adalah proses mendapatkan pengetahuan, keterampilan dan sikap.

Beetlestone (Farida N, 2014: 11) menyatakan bahwa 'kreatif berarti melibatkan pengungkapan gagasan dan perasaan serta penggunaan berbagai macam cara untuk menemukan, mengeksplorasi, dan mencari kepastian untuk menyelesaikan suatu permasalahan'. Sedangkan Munandar (Sari dkk, 2016: 126) menyatakan 'Sikap kreatif adalah cara seseorang menerima atau menolak sesuatu yang didasarkan pada pandangan kecenderungan mental yang relatif menetap seperti untuk memberikan gagasan yang baru, melakukan hal-hal dengan caranya sendiri dalam memecahkan masalah, mepertanyakan segala sesuatu, dan mengambil resiko dalam membuat sebuah keputusan'. Dalam konteks demikian diperlukan model dan metode yang inovatif, proses pembelajaran akan berlangsung aktif, efektif, dan menyenangkan.

Model pembelajaran merupakan bentuk pembelajaran yang tergambar dari awal sampai akhir yang disajikan secara khas oleh guru. Dengan kata lain model pembelajaran bingkai dari penerapan suatu pendekatan, metode dan teknik pembelajaran. Fathurrahman (2015: 29) menyebutkan bahwa model pembelajaran yaitu kerangka konsepual yang mendeskripsikan dan melukiskan prosedur yang sistematis dalam mengorganisasikan pengalaman belajar untuk mencapai tujuan belajar tertentu dan berfungsi sebagai pedoman dalam perencanaan pembelajaran. Hal ini sejalan dengan pendapat Enggan dan Kauchak dalam Trianto (2015: 24) bahwa model pembelajaran memberikan kerangka dan arah bagi guru untuk mengajar.

Namun pada kenyataannya menciptakan suasana kelas yang kondusif dan menciptakan sistem pembelajaran yang menumbuhkan rasa cinta siswa terhadap suatu mata pelajaran dan membuat siswa merasa senang ketika berada di kelas ternyata sulit dilakukan, tidak banyak guru yang berhasil membuat para siswa termotivasi dan merasa senang ketika berada di kelas. Hal ini terjadi karena sistem pembelajaran yang dilakukan oleh guru cenderung membosankan dan monoton bahkan kebanyakan guru hanya menggunkan metode ceramah sehingga siswa merasa jenuh dan mengantuk pada saat pembelajaran berlangsung.

Berdasarkan hasil observasi di kelas IV A pada tanggal 22 Januari 2019 - 
16 Maret 2019 pada semester Ganjil, guru mengajar menggunakan metode ceramah dan penugasan. Pembelajaran diawali dengan ceramah dan mencatat, kemudian siswa diminta mengerjakan soal latihan yang ada di buku pegangan siswa. Siswa masih pasif dan kurang berperan dalam pembelajaran sehingga siswa cenderung menerima apa saja yang disampaikan guru. Siswa terlihat kurang bersemangat untuk belajar. Ada beberapa anak yang kurang memperhatikan penjelasan guru, siswa cenderung asyik bermain bolpoint atau pensil terkadang juga bercakap-cakap dengan teman sebangkunya saat proses pembelajaran. Beberapa siswa terlihat bosan dan mengantuk saat proses pembelajaran.

Sementara itu hal yang sama juga terlihat di kelas IV B, dalam mengajar guru sama-sama menggunakan metode ceramah dan penugasan. Pembelajaran diawali dengan ceramah, kemudian siswa diminta mengerjakan soal latihan yang diberikan guru. Pada saat guru mengajar, ada beberapa siswa yang bercakap-cakap dengan temannya dan menganggu temannya belajar. Sering kali guru mengingatkan agar memperhatikan penjelasannya. Saat pembelajaran siswa terlihat bosan dan mengantuk.

Melihat hasil observasi di atas, guru sebaiknya membangkitkan kreativitas belajar siswa agar siswa berpartisipasi aktif da kreatif dalam pembelajaran IPA. Dalam meningkatkan kreativitas belajar IPA dapat dilakukan dengan model pembelajaran berbasis masalah atau Problem Based Learning (PBL). Karakteristik pembelajaran IPA (Ilmu Pengetahuan Alam) adalah berupaya mengenali proses kehidupan nyata di lingkungan. Oleh karena itu, observasi dan eksperimen penting dalam mempelajari IPA. Kemampuan observasi sangat diperlukan untuk melakukan eksplorasi terhadap lingkungan. Guru perlu memilih media yang sesuai agar pembelajaran tidak hanya sekedar kumpulan konsep. Salah satu cara yang ditempuh untuk mengaktifkan siswa dan memberikan pengalaman kepada siswa adalah dengan menggunakan model pembelajaran problem based learning (PBL).

Pembelajaran problem based learning (PBL) berarti pembelajaran berbasis masalah. Secara istilah problem based learning (PBL) adalah suatu pendekatan pembelajaran yang dimulai dengan menyelesaikan suatu masalah, tetapi untuk menyelesaikan suatu masalah pesertadidik memerlukan pengetahuan baru untuk dapat menyelesaikannya. Pembelajaran problem based learning (PBL) merupakan konsep belajar yang menolong siswa untuk meningkatkan keterampilan yang dibutuhkan pada eraglobalisasi saat ini. Oleh 
Barrows, Howard

(1986)

dan kedalam

kemudian diadaptasi

$$
\text { (1995). }
$$

Pembelajaran dengan model

problem based learning (PBL)

menghadirkan situasi nyata kehidupan siswa sehingga siswa tidak bingung dan dapat langsung memahami dan menemukan sendiri apa yang dipelajari khususnya pada pembelajaran IPA. Model pembelajaran ini juga banyak melibatkan siswa secara aktif dalam proses pembelajaran. Siswa diberikan kebebasan untuk lebih berpikir dalam mengembangkan penalarannya tersebut dalam menyelesaikan permasalahan yang dihadapinya.

Pembelajaran IPA kelas IV di SDN

Kalisari 01 Sayung Demak masih menggunakan model ceramah dan diskusi dalam pembelajaran. Diskusi yang dilakukan masih belum mampu membuat siswa aktif secara maksimal. Kegiatan diskusi mengajak siswa untuk mencari materi dari beberapa referensi buku. Sedangkan ketika presentasi hasil diskusi, siswa yang lain kurang memperhatikan karena merasa sudah memiliki materimateri yang disajikan meskipun belum paham sepenuhnya. Hal inilah yang membuat siswa monoton menggali materi, kurang mendapat pengalaman langsung, belum mampu menemukan konsep sendiri, dan kurang aktif.
Berdasarkan uraian di atas, maka penulis telah melakukan penelitian dengan Pengaruh Kreativitas Siswa dalam Model Pembelajaran Problem Based Learning Terhadap Prestasi Belajar Siswa pada Mata Pelajara IPA. Tujuan penelitian ini adalah untuk mengetahui pengaruh kreativitas siswa dalam model pembelajaran problem based learning terhadap prestasi belajar siswa pada mata pelajaran IPA kelas IV SDN Kalisari 01.

\section{METODE PENELITIAN}

Pada rancangan penelitian ini, pendekatan yang digunakan adalah pendekatan eksperimen. Penelitian ini menggunakan quasi experimental design. Penelitian ini mengambil bentuk desainnya adalah nonequivalent control group design dengan dua kelompok yaitu kelompok kontrol dan kelompok eksperimen. Kelompok kontrol adalah kelompok yang diberikan perlakuan model ceramah, sedangkan kelompok eksperimen adalah kelompok yang diberikan perlakuan model Problem Based Learning. Teknik analisis data dalam penelitian eksperimen menggunakan perhitungan statistik. Untuk perhitungan data menggunakan bantuan SPSS 24.00 for windows. Dalam penelitian ini, peneliti mengambil populasi seluruh siswa kelas IV A yang berjumlah 33 orang dan IV B yang berjumlah 33 orang agar penelitian bisa lebih akurat. Ada beberapa 
jenis teknik pengumpulan data yang akan digunakan oleh peneliti yaitu tes dan nontes. Instrumen penelitian yang digunakan yaitu lembar tes prestasi belajar dan lembar observasi. Instrumen tersebut sudah diujikan validitas isinya kepada beberapa validator dan disebarkan kepada subjek penelitian lalu mengambil data. Validitas adalah ukuran yang menunjukan tingkat keabsahan atau kesahihan suatu instrumen.

\section{HASIL DAN PEMBAHASAN}

\section{Hasil Penelitian}

Hasil penelitian yang diperoleh menggambarkan penelitian yang telah dilakukan. Data hasil penelitian yang telah diperoleh selanjutnya dianalisis untuk mengintrepretasikan data yang telah terkumpul sekaligus menjawab hipotesis penelitian. Berikut ini merupakan penjelasan dari hasil observasi sikap kreatif siswa, prestasi belajar siswa, data awal, dan data akhir kelas IV SDN Kalisari 01.

\section{Hasil Observasi Sikap Kreatif Siswa}

Perhitungan lembar observasi minat siswa pada kelas eksperimen dinilai dari pengamatan 2 observer (guru kelas dan teman sejawat) selama proses pembelajaran di kelas eksperimen berlangsung. Indikator yang diukur dalam penelitian ini adalah sebagai berikut:
1) Pengetahuan dialami, dipelajari, dan ditemukan oleh siswa,

2) Siswa melakukan sesuatu untuk memahami materi pelajaran (membangun pemahaman),

3) Siswa mengkomunikasikan sendiri hasil pemikirannya dan

4) Siswa berpikir reflektif.

\section{Prestasi Belajar Siswa}

Berdasarkan penjelasan hasil pre test pada kelas IVA dan IVB, diperoleh jumlah nilai keseluruhan pre test dari kelas IVA diperoleh 2214 dengan rata-rata 67,09 dan pada kelas IVB diperoleh 1999 dengan rata-rata 64,48 . Rata-rata nilai pre test yang diperoleh kelas IVA sedikit lebih unggul dari pada rata-rata kelas IVB. Oleh karena itu, kelas IVB dijadikan sebagai kelas eksperimen, dan kelas IVA dijadikan sebagai kelas kontrol. Hasil pretest pada kedua kelas selanjutnya dianalisis dengan uji normalitas, uji homogenitas, dan uji kesamaan dua rata-rata sebagai pemenuhan uji syarat sampel yang akan dijelaskan pada subbab analisis data.

Berdasarkan penjelasan hasil post test pada kelas kontrol dan eksperimen, diperoleh jumlah nilai keseluruhan Post test dari kelas eksperimen (IVB) diperoleh 3100 dengan rata-rata 93,93 dan pada kelas kontrol (IVA) diperoleh 3035 dengan ratarata 91,96. Hal ini menunjukkan adanya 
pengaruh model pembelajaran Problem

Based Learning (PBL) terhadap prestasi belajar siswa.

\section{Pengujian Hipotesis}

Sebelum pengujian hipotesis terlebih dahulu harus dilakukan uji prasyarat yaitu dengan melakukan:

1) Uji Normalitas

Sebelum uji hipotesis dengan menggunakan regresi linier terlebih dahulu data posttest harus diuji normalitaskan. Uji normalitas dilakukan untuk melihat tingkat kenormalan data hasil posttest dengan menggunakan teknik One Sample Kolmogrov Smirnov Test. Uji Normalitas tersebut bertujuan untuk mengetahui normal atau tidaknya distribusi variabel penelitian. Pedoman pengambilan keputusan adalah jika nilai signifikasi (sig) dari kolom Kolmogrov Smirnov $<0,05$ maka kesimpulannya tidak berdistribusi normal. Jika nilai signifikasi (sig) dari kolom kolmogorov smirnsov > 0,05 maka data berdistribusi normal (Priyatno, 2012: 36). Adapun hasil uji normalitas posttest dapat dilihat pada tabel 1.1.

Tabel 1.1. Uji Normalitas

\begin{tabular}{llr}
\hline \multicolumn{3}{c}{ One-Sample Kolmogorov-Smirnov Test } \\
\hline & \multicolumn{1}{c}{$\begin{array}{c}\text { Unstandardized } \\
\text { Residual }\end{array}$} \\
\hline $\mathrm{N}$ & \multicolumn{1}{c}{33} \\
\hline Normal Parameters ${ }^{\mathrm{a}, \mathrm{b}}$ & Mean &, 0000000 \\
\cline { 2 - 3 } & Std. &, 088 \\
\hline Most Extreme & Deviation &, 050 \\
Differences & Absolute &,- 088 \\
\cline { 2 - 3 } & Positive &, 088 \\
\cline { 2 - 3 } & Negative &, $200^{\mathrm{c}, \mathrm{d}}$ \\
\hline Test Statistic & & \\
\hline Asymp. Sig. (2-tailed) & & \\
\hline a. Test distribution is Normal. & \\
\hline b. Calculated from data. & & \\
\hline c. Lilliefors Significance Correction. & \\
\hline d. This is a lower bound of the true significance. & \\
\hline
\end{tabular}


Hasil output penelitian yang telah dijelaskan di atas dapat diketahui bahwa nilai signifikasi dari kolom kolmogorov-smirnov > 0,05 yaitu 0,200 Karena signifikasi dari posttest > 0,05 maka dapat disimpulkan bahwa distribusi data posttest penelitian ini dinyatakan normal. Selanjutnya dapat dilihat pada lampiran.

2) Analisis Regresi Linier Sederhana

Uji hipotesis dilakukan untuk mengetahui pengaruh yang positif dari kreativitas siswa dalam model pembelajaran Problem based learning (PBL) terhadap prestasi belajar siswa kelas IV SDN Kalisari 01 Uji regresi sederhana dilakukan untuk mengetahui seberapa besar pengaruh kreativitas siswa dalam model pembelajaran Problem based learning (PBL) terhadap prestasi belajar siswa kelas IV SDN Kalisari 01. Perhitungannya dilakukan dengan menggunakan SPSS 24.00 dengan taraf signifikasi $5 \%$. Hipotesis untuk regresi linier adalah sebagai berikut:

$\mathrm{H}_{\mathrm{o}} \quad$ : Tidak terdapat pengaruh dalam kreativitas siswa terhadap prestasi belajar dengan menggunakan model pembelajaran Problem based learning (PBL) dan perbedaan hasil belajar pada pelajaran IPA kelas IV SDN Kalisari 01 Sayung Demak.

$\mathrm{H}_{\mathrm{a}} \quad$ : Terdapat pengaruh dalam kreativitas siswa terhadap prestasi belajar dengan menggunakan model pembelajaran Problem based learning (PBL) dan perbedaan hasil belajar pada pelajaran IPA kelas IV SDN Kalisari 01 Sayung Demak.

Selanjutnya untuk mengetahui koefisien determinasi dapat dilihat pada output coeffisients pada tabel 1.2.

Tabel 1.2. Hasil Koefisien Determinasi

\begin{tabular}{|c|c|c|c|c|c|c|}
\hline \multicolumn{7}{|c|}{ Coefficients $^{\mathbf{a}}$} \\
\hline \multirow{3}{*}{\multicolumn{2}{|c|}{ Model }} & \multirow{2}{*}{\multicolumn{2}{|c|}{$\begin{array}{c}\text { Unstandardized } \\
\text { Coefficients }\end{array}$}} & \multirow{3}{*}{$\begin{array}{c}\text { Standardized } \\
\text { Coefficients } \\
\text { Beta }\end{array}$} & \multirow[t]{3}{*}{$\mathrm{T}$} & \multirow[t]{3}{*}{ Sig. } \\
\hline & & & & & & \\
\hline & & B & Std. Error & & & \\
\hline \multirow[t]{2}{*}{1} & (Constant) & 44,209 & 35,406 & & 1,249 & ,221 \\
\hline & Postest & ,228 & ,376 & , 109 & ,608 & ,547 \\
\hline
\end{tabular}

a. Dependent Variable: pretest 
Berdasarkan hasil persamaan regresi linier sederhana di atas, menunjukan bahwa nilai konstanta (a) adalah 44,209 artinya jika koefisien pengaruh kreativitas siswa dalam model pembelajaran Problem based learning (PBL) bernilai 0, maka prestasi belajar siswa bernilai 44,209. Sementara itu nilai koefisien regresi variabel kreativitas siswa dalam pembelajaran Problem Based Learning (PBL) yaitu 0,228 makan dapat dikatakan setiap adanya peningkatan satuan kreativitas siswa dalam pembelajaran Problem Based Learning (PBL) maka Prestasi belajar siswa sebesar 0,228. Dengan demikian, dapat disimpulkan bahwa pengaruh kreativitas siswa dalam pembelajaran Problem Based Learning (PBL) berpengaruh terhadap Prestasi belajar siswa.

Berdasarkan uji $\mathrm{t}$ diketahui $\mathrm{t}_{\text {hitung }}$ sebesar 0,608 dan $\mathrm{t}_{\text {tabel }}$ sebesar 1,693 (lihat $\mathrm{t}$ tabel) karena nilai $t_{\text {hitung }}$ lebih kecil dari nilai $t_{\text {tabel}}$, jadi kreativitas siswa dalam pembelajaran Problem Based Learning (PBL) tidak berpengaruh secara parsial terhadap prestasi belajar.

Selanjutnya untuk mengetahui seberapa besar pengaruh kreativitas siswa dalam pembelajaraan Problem Based Learning (PBL) terhadap prestasi belajar dapat dilihat pada output Model Summary pada nilai R Square Tabel 1.3.

\section{Tabel 1.3 Besar Pengaruh kreativitas siswa dalam Pembelajaran Problem Based Learning terhadap Prestasi Belajar}

\begin{tabular}{ccccc}
\hline \multicolumn{4}{c}{ Model Summary } \\
\hline Model & $\mathrm{R}$ & $\mathrm{R}$ & Adjusted R & Std. Error of \\
& & Square & Square & the Estimate \\
\hline 1 &, $790^{\mathrm{a}}$ &, 660 &, 280 & 17,29945 \\
\hline \multicolumn{4}{c}{ a. Predictors: (Constant), posttest } \\
\hline
\end{tabular}

Regresi sederhana huruf $R$ di peroleh $r_{\text {tabel }}$ 0,300 Sehingga dapat menunjukan korelasi sederhana antara dinyatakan bahwa $r_{\text {hitung }}>r_{\text {tabel }}(0,790>$ variabel X (Kreativitas siswa dalam pembelajaran Problem Based Learning terhadap variabel Y (Prestasi Belajar), nilai $r_{\text {hitung }}$ di atas didapatkan 0,790 jika dibandingkan dengan $\mathrm{r}_{\text {tabel }}$ dimana $\mathrm{df}=\mathrm{n}$ $0,300)$, jadi terdapat hubungan yang signifikan antara variabel $\mathrm{X}$ (kreativitas siswa dalam pembelaaran Problem Based Learning) terhadap variabel $\mathrm{Y}$ 2 dengan taraf signifikasi $5 \%$ atau 0,05 (Prestasi Belajar).

38 | Jurnal Ilmiah "Pendidikan Dasar" Vol. VII No. 1 Januari 2020 
R Square $\left(\mathrm{R}^{2}\right)$ atau kuadrat dari $\mathrm{R}$ menunjukan koefisien determinasi. Angka ini akan diubah kebentuk persen, artinya persentase sumbangan pengaruh variabel independen terhadap variabel dependen. Nilai $\mathrm{R}^{2}$ sebesar 0,660 artinya persentase sumbangan pengaruh variabel kreativitas siswa dalam pembelajaran Problem Based Learning (PBL) terhadap prestasi sebesar 66\% sedangkan sisanya $34 \%$ dipengaruhi oleh faktor lain yang tidak dimasukan dalam penelitian ini.

Adjusted R Square adalah $\mathrm{R}$ Square yang telah disesuaikan sebesar 0,660 menunjukan sumbangan pengaruh. Std Eror Of The Estimate adalah ukuran kesalahan prediksi nilai sebesar 17,29945 kesalahan dalam memprediksi pretest sebesar 17,29945.

\section{Pembahasan}

Sikap Kreatif atau kreativitas sangat diperlukan di dalam pendidikan terutama dalam pembelajaran. Berdasarkan pengujian hipotesis yang telah dilakukan, menunjukan bahwa model Problem based learning (PBL) berpengaruh terhadap prestasi belajar. Pengaruh model Problem Based Learning (PBL) yang diperoleh berdasarkan pengujian hipotesis sebesar $66 \%$. Hasil penelitian serupa yang dilakukan menunjukan adanya pengaruh

Problem Based Learning (PBL) terhadap kemandirian belajar sebesar 79,3 \% oleh Evi Tri Wulandari (2015). Selain itu penelitian serupa juga menunjukan adanya pengaruh model Problem Based Learning (PBL) terhadap kemampuan berpkir kritis siswa dilakukan oleh Devi Diyas Sari (2012). Selanjutnya, penelitian yang menunjukan adanya pengaruh model pembelajaran Problem Based Learning (PBL) terhadap hasil belajar. Hasil penelitian serupa terbukti bahwa hasilnya berpengaruh sehingga model Pembelajaran Problem Based Learning (PBL) baik digunakan dalam pembelajaran dilakukan oleh Khafid Alwi (2017).

Fase-fase pembelajaran dengan menggunakan model Problem based learning dalam penelitian ini pada kelas eksperimen (IVB) diawali dengan, pertama, guru mengajak siswa untuk mengamati magnet. Siswa disuruh untuk mengamati magnet beserta benda-benda yang dapat ditarik magnet dan yang tidak dapat ditarik magnet. Kemudian Guru menjelaskan pengertian magnet, komponen-komponen magnet, macammacam magnet, dan materi lain tentang magnet. Sambil membuat siswa lebih penasaran dan membuat siswa lebih antusias dalam pembelajaran guru

39 | Jurnal Ilmiah “Pendidikan Dasar” Vol. VII No. 1 Januari 2020 
memberikan demonstrasi cerita untuk memunculkan sebuah masalah yang memotivasi siswa untuk terlibat dalam pemecahan masalah tersebut.

Kedua, guru mengajak siswa untuk mengamati benda-benda yang dapat ditarik oleh magnet dan bendabenda yang tidak dapat ditarik magnet dan mengelompokannya. Kemudian guru mengordinir siswa untuk melakukan belajar dengan membuat suatu kelompok belajar. Pembagian kelompok ini ditujukan untuk memudahkan siswa dalam melakukan pembelajaran sehingga ada kerja sama yang terjalin antar setiap siswa dalam melakukan pengamatan.

Ketiga, guru menjelaskan langkah-langkah pembelajaran dengan model Problem based learning, (PBL) siswa diharapkan dapat memahami setiap langkah-langkah yang ada. Penjelasan ini dimudahkan untuk memudahkan siswa dalam memahami setiap fase yang ada pada pembelajaran dengan Model Problem based learning (PBL).

Keempat, siswa diberikan tugas untuk membuat karya yang nyata yaitu mengelompokan benda-benda magnetis dan non magnetis dalam sebuah gambar disertai alasannya serta menjelaskan manfaat maagnet dalam kehidupan sehari-hari.
Langkah selanjutnya yaitu langkah kelima, adalah memberikan kesempatan kepada siswa untuk mempersentasikan karya tersebut dan siswa lain memberikan pendapat mengenai apa yang dipersentasikan. Selain itu guru juga memberikan kesempatan kepada siswa untuk menanyakan hal-hal yang kurang dimengerti tentang materi yang dipeajari.

Data pendukung diperoleh dari pengamatan terhadap siswa saat proses pembelajaran berlangsung, seorang pengamat mengamati. Pengamat membawa suatu perangkat pedoman observasi kreativitas siswa dan proses pembelajaran dengan Problem based learning (PBL). Secara umum penerapan model Problem based learning (PBL) sudah baik. Siswa memahami konsep yang diajarkan, aktif dalam memecahkan masalah dan menuntut kreativitas berpikir siswa yang lebih tinggi. Guru tetap melakukan arahan kepada siswa serta melakukan evaluasi terhadap penyelidikan mereka dan proses-proses yang mereka gunakan.

Pada pembelajaran sebelum menggunakan model Problem based learning (PBL) ini guru hanya menyampaikan materi dengan metode ceramah saja, sehingga materi hanya 
sekedar dari penjelasan guru saja. Tetapi dengan menggunakan model Problem based learning (PBL) menerapkan pembelajaran yang berbeda dari sebelumnya. Model Problem based learning (PBL) ini membuat siswa dapat merasakan manfaat pembelajaran, karena masalah-masalah yang diselesaikan langsung dikaitkan dengan kehidupan yang nyata, hal ini bisa meningkatkan motivasi siswa terhadap bahan yang dipelajarinya.

Berdasarkan antusias siswa dengan melihat hasil observasi pembelajaran model Problem based learning (PBL) pada materi gaya magnetis dan nonmagnetis dapat diambil kesimpulan bahwa pembelajaran dengan menggunakan model Problem based learning (PBL) baik digunakan dalam pembelajaran. Siswa didorong untuk lebih mandiri dan dewasa, berpikir kreatif, memberi aspirasi dan menerima pendapat orang lain serta menambahkan sikap sosial siswa sehingga prestasi belajar lebih baik dari keadaan awal. Hal ini sejalan dengan penelitian yang dilakukan oleh Desi Resita Merayu Sukma, Lilik Sabdaningtyas dan Fitria Akhyar (2018) yang menunjukan bahwa pembelajaran dengan menggunakan model Problem based learning (PBL) dapat meningkatkan prestasi belajar siswa.
Terbukti dengan adanya peningkatan belajar dari sebelum perlakuan dan setelah perlakuan dengan menggunakan Problem based learning (PBL). Jadi dapat disimpulkan bahwa terdapat perbedaan hasil belajar siswa sebelum menggunakan model Problem Based Learning dan sesudah menggunakan model Problem Based Learning, hal ini berarti terdapat pengaruh model Problem Based Learning terhadap hasil belajar siswa pada pembelajaran. Penelitian lain juga dilakukan oleh Derin Nurfajriyah, Ani Nur Aeni dan Asep Kurbia Jayadinata (2016). Hasil penelitian menunjukan bahwa, pembelajaran IPA dengan menggunakan model problem based learning terbukti dapat meningkatkan kemampuan berpikir kreatif siswa pada materi pesawat sederhana.

\section{SIMPULAN}

Berdasarkan hasil penelitian mengenai pengaruh kreativitas siswa dalam model pembelajaran Problem Based Learnig (PBL) terhadap prestasi belajar siswa kelas IV dapat ditarik kesimpulan sebagai berikut: 1) Terdapat Pengaruh Kreatifitas Siswa dalam Model Pembelajaran Problem Based Learning (PBL) dengan hasil $66 \%$. Hal tersebut berarti kreatifitas siswa dalam model pembelajaran Problem Based

41 | Jurnal Ilmiah "Pendidikan Dasar” Vol. VII No. 1 Januari 2020 
Learning (PBL) baik. 2) Prestasi belajar IPA pada siswa kelas IV SD Negeri Kalisari 01 materi gaya magnetis dan non-magnetis dengan menerapkan model pembelajaran Problem Based Learning (PBL) berpengaruh terhadap prestasi belajar siswa yang diperoleh dari rata-rata kelas eksperimen 93,93 dan pada kelas kontrol dengan rata-rata 91,96. Hal ini menunjukkan adanya pengaruh model pembelajaran Problem Based Learning (PBL) terhadap prestasi belajar siswa. Berdasarkan kesimpulan di atas maka saran yang dapat diberikan adalah 1) Guru diharapkan dapat menerapkan model pembelajaran dan media pembelajaran yang lebih baik dan menyenangkan agar tercipta pembelajaran yang PAIKEM (Pembelajaran Aktif, Inovati, Kreatif, Efektif dan Menyenangkan), 2) Kreativitas dan prestasi belajar pada siswa merupakan unsur yang sangat penting untuk dikembangkan agar proses belajar mengajar dapat berjalan dengan lancar.

\section{DAFTAR PUSTAKA}

Afandi, M., Chamalah, E., \& Puspita, O. (2013). Model dan Metode Pembelajaran di Sekolah. Semarang: UNISSULA Press.

Ahmadi, A. \& Widodo, S. 2013. Psikologi Pendidikan. Jakarta: PT. Rineka Cipta.
Al-Tabany, T.I.B. 2014. Mendesain Model Pembelajaran Inovatif, Progresif dan Kontekstual. Jakarta: Prenadamedia Group.

Arifin, Z. 2013. Penelitian Pendidikan. Bandung: PT Remaja Rosdakarya

Arikunto, S. 2010. Metode Penelitian Kuantitatif, Kualitatif dan $R \& D$. Jakarta: Bumi Aksara.

Dimyati \& Mudjiono. 2002. Belajar dan Pembelajaran. Jakarta: Rineka Cipta.

Duch,B.J.,Groh,S.E， \& Allen,D.E.(EDS). 2001. The Power Of Problem Based Learning. Sterlig,VA: Stylus.

Farida, N. 2014.Pengaruh sikap Kreatif Terhadap Prestasi Belajar matematika. Jurnal Nasional Pendidikan Matematika. 3, (2), 10-15, Lampung: FKIP Univ. Muhammadiyah Metro.

Fathurrohman, $\quad$ M. 2015. Model Pembelajaran Inovatif. Yogjakarta: Ar-Ruz Media.

Hanafiah, N., \& Cucu, S. 2010. Konsep Strategi Pembelajaran. Refika Aditama. Bandung.

Inel, D., \& Balim, A.G. 2010. The effects of using problem-based learning in science and technology teaching upon students' academic achievement and levels of structuring concepts. Turkey: Asia-Pacific Forum on Science Learning and Teaching, Vol. 11.

Iskandar, S.M. 1996. Pendidikan Ilmu Pengetahuan Alam. Jakarta. PT. Raja Grasindo Persada.

Kamisa. 1997. Kamus Lengkap Bahasa Indonesia, Surabaya: Kartika.

42 | Jurnal Ilmiah "Pendidikan Dasar” Vol. VII No. 1 Januari 2020 
Margono. 2010. Metodologi Penelitian Pendidikan. Jakarta: Rineka Cipta. Pendidikan, Jakarta: Kencana.

Musriadi, R. 2016. Implementation of Problem Based Learning Model in Concept Learning Mushroom as a Result of Student Learning Improvement Efforts Guidelines for Teachers. University serambi Mekah: Journal of education and practice. Vol.7, No. 22.

Nurfajriyah, D, Aeni, A.N, \& Jayadinata, A.K. 2016. Pengaruh Model Problem Based Learning Terhadap Kemampuan Berpikir Kreatif Siswa Pada Materi Pesawat Sederhana. Jurnal Pena Ilmiah: Vol. 1, No. 1 (2016)

Poerwadarminta. 2007. Kamus Umum Bahasa Indonesia. Jakarta: PN Balai. Pustaka.

Riduwan. 2014. Dasar-Dasar Statistika. Bandung: Alfabeta.

Sanjaya, W. 2006. Strategi Pembelajaran Berorientasi Standar Proses. Jakarta: Kencana

Sardiman A.M. 2011. Interaksi dan Motivasi Belajar Mengajar, Jakarta: Rajawali Pers.

Slameto. 2010. Belajar dan Faktor-Faktor yang Mempengaruhinya, Jakarta: Rineka Cipta.

Sokol A, Gozdeka A, dan Figurska I. (2015). "The importance of teacher leadership in shaping the creative attitudes of students". International Journal for Social and Behavioral Science 197. $1976-1982$.
Sugiyanto. 2010. Model-Model Pembelajaran Inovatif, Surakarta: Yuna Pustaka.

Sugiyono. 2016. Metodologi Penelitian Pendidikan, Bandung : Alfabeta.

Sukma, Desi Resita Merayu dkk. 2018. Pengaruh Model Problem Based Learning Terhadaphasil Belajar Siswa Kelas Iv Pada Pembelajaran Tematik, Jurnal Universitas Lampung Fakultas Keguruan dan Ilmu Pendidikan.

Sulaiman, Y. 2011. The Effect of Problem Based Learning on Critical Thinking Ability: A Theoretical and Empirical Review. Malaysia: International Review of Social Sciences and Humanities Vol.2, No.1.

Tu'u, T. 2000. Peran Disiplin terhadap Prestasi Belajar. Yogyakarta: Pustaka Pelajar.

Zaduqisti, E. 2010. Problem Based Learning (Konsep Ideal Model Pembelajaran untuk Meningkatkan Prestasi Belajar dan Motivasi Belajar, Jurnal Forum Tarbiyah, Vol 8, No. 2 : Desember 2010. 